\title{
Coliphages as indicators of fecal contamination in wastewater treatment (SCA.Re.S. Project)
}

\author{
Osvalda De Giglio ${ }^{1}$, Ileana Federigi ${ }^{2}$, Marco Verani ${ }^{2}$, Giusy Diella ${ }^{1}$, Francesco Triggiani ${ }^{1}$, Carla Calia ${ }^{1}$, Francesca \\ Apollonio ${ }^{1}$, Giusy Bonanno Ferraro ${ }^{3}$, Pamela Mancini ${ }^{3}$, Carolina Veneri ${ }^{3}$, La Rosa Giuseppina ${ }^{3}$, Annalaura Car- \\ ducci $^{2}$ and Maria Teresa Montagna ${ }^{1}$
}

\author{
${ }^{1}$ Regional Reference Laboratory of Clinical and Environmental Surveillance of Legionellosis, Department of \\ Biomedical Science and Human Oncology, University of Bari Aldo Moro, Piazza G. Cesare 11, 70124 Bari, Italy \\ ${ }^{2}$ Laboratory of Hygiene and Environmental Virology, Department of Biology, University of Pisa, Via S. Zeno \\ 35/39, 56127 Pisa, Italy \\ ${ }^{3}$ Department of Environment and Health, Istituto Superiore di Sanità, Rome, Italy
}

Publisher's Note: MDPI stays neutral with regard to jurisdictional claims in published maps and institutional affiliations.

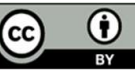

Copyright: (c) 2020 by the authors. Submitted for possible open access publication under the terms and conditions of the Creative Commons Attribution (CC BY) license (http://creativecommons.org/licenses /by/4.0/).
Abstract: Bacteriophages are fecal indicators of viral contamination, because they are more similar to human pathogenic viruses than the traditional fecal indicator bacteria, in terms of log-reduction during wastewater treatment and persistence in the aquatic environment. The aim of this study was to evaluate the presence of bacteriophages and enteric viruses: Enterovirus, Adenovirus, Norovirus, Hepatitis A and E, Rotavirus and Pepper mild mottle virus (PMMoV), in the context of SCA.Re.S. (Evaluation of sanitary risk related to the discharge of wastewater to the ground) project. The investigation focused on a wastewater treatment plant located in an area fractured by karst in the Salento peninsula (Apulia, Italy). In autumn (September-November) 2019, water samples were monthly collected from three sites (treated wastewater, infiltration trench and monitoring well). The somatic coliphage were analyzed by standardized culture-based methods, according to BS EN ISO 10705-2:2001. Coliphage density was enumerated using plaque assay method on appropriate host bacteria (E. coli Famp) and expressed as plaque forming units PFU/100mL. Nested RT-PCR assay was used for detection of enteric viruses. The median values of coliphages were $590 \mathrm{PFU} / 100 \mathrm{~mL}$ in treated wastewater, $1000 \mathrm{PFU} / 100 \mathrm{~mL}$ in infiltration trench while all samples from monitoring well were under the detection limit. All samples were positive for at least one viral pathogen. PMMoV was detected only in monitoring well. The results confirmed the role of coliphages as indicators of viral contamination. Overall, we observed a gradual reduction in the concentration/occurrence of coliphages and viruses across the karst-fissured soil, until the complete removal in the monitoring well. Different soil properties are probably involved in this phenomenon such as straining, soil pores, microorganism size, and adsorption onto soil particle. Moreover, we can also hypothesize natural degradation over time, phototoxicity or ingestion by multicellular organisms in the soil and/or monitoring well water. 